Research Article

\title{
Open-Closed-Loop Iterative Learning Control with the System Correction Term for the Human Soft Tissue Welding Robot in Medicine
}

\author{
Yang Wu $\mathbb{D}^{1}{ }^{1}$ Min Yang, ${ }^{1}$ and Jiancheng Zhang ${ }^{2}$ \\ ${ }^{1}$ School of Intelligent Equipment Engineering, Wuxi Taihu University, Wuxi, Jiangsu 214064, China \\ ${ }^{2}$ School of Science, Jiangnan University, Wuxi, Jiangsu 214122, China \\ Correspondence should be addressed to Yang Wu; wuyangwxu@yandex.com
}

Received 9 July 2020; Revised 23 November 2020; Accepted 12 December 2020; Published 22 December 2020

Academic Editor: Luis Payá

Copyright (c) 2020 Yang Wu et al. This is an open access article distributed under the Creative Commons Attribution License, which permits unrestricted use, distribution, and reproduction in any medium, provided the original work is properly cited.

By combining manual welders (with intelligence and versatility) and automatic welding systems (with accuracy and consistency), an intelligent welding system for human soft tissue welding can be developed in medicine. This paper presents a data-correction control approach to human welder intelligence, which can be used to control the automated human soft tissue welding process. Human soft tissue welding can preconnect the excised tissue, and the shape of the tissue at the junction ensures the recovery of the operative organ function. This welding technology has the advantages of rapid operation, minimal tissue damage, no need for suture materials, faster recovery of the mechanism and properties of the living tissue, and the maintenance of the function of the organs. Model of the welding system is identified from the data; an open-closed-loop iterative learning control algorithm is then proposed to improve the tracking accuracy of the system. The algorithm uses the tracking error of current and previous to update the control law. Meanwhile, to further improve the accuracy under the conditions of external interference, a system correction term is added to the proposed ILC algorithm, which can be adjusted according to the system's errors and output and improve the capability of the target tracking greatly. A detailed convergence analysis for the ILC law has been given. Simulation results verify the feasibility and effectiveness of the proposed method for GTAW control tasks.

\section{Introduction}

Automatic welding [1-3] is a welding process which has been widely used in precision and stable joining. It is primarily used for applications with the appropriate degree of overall penetration that are critical to services. The automation system relies on accurate control of joint assembly [4] and welding conditions [5-7] and tedious programming of welding parameters [8] to produce repeatable results. With the progress and development of welding technology, automatic control is adopted to improve the welding quality monitoring and has become an important direction of the development of the welding technology. In the development and application of welding automation, how to ensure welding quality under the premise of meeting basic requirements has become the focus of attention. Focusing on welding quality issues, many domestic and foreign welding research works [9-11] have invested a lot of manpower and material resources, including arc height control [12], weld automatic tracking control $[13,14]$, and welding penetration control [15-17]. Through the application of various automatic control technologies, the welding process is automatically controlled to ensure the normal progress of the welding process.

In recent decades, the welding process control of automatic welding has been the focus of scholars. Despite the success in monitoring and sensing the welding process, control algorithm of the weld penetration remains difficult. Di et al. [18] combined the neural network and fuzzy logic control technology to realize the control of welding process. This method simplifies the fuzzy law and improves the adaptability of the member functions used in advanced 
welding process. The results show that this method is very effective in the welding process control of regular welds. In the nonlinear compensation technology of robot control, Gao et al. [19] adopted a robot welding seam tracking neural network controller based on the Cartesian space trajectory. The neural network can be directly used in arc welding robot trajectory planning without modifying the internal structure of the existing controller of the arc welding robot. Based on the welding car, Yan et al. [20] proposed a visual control method for the starting point of welding seam, which used the binocular vision to detect the welding torch and welding seam. After image processing and identification, the deviation between the position of the welding torch and the position of the welding seam was obtained. However, the final accuracy of this method still depends on the measurement accuracy of the visual system. When the initial point of a wide $\mathrm{V}$-shaped weld is identified, a better effect can be obtained.

The welding mentioned above is related to the industry, but the welding that we are talking about is applied to the biomedical field. The Welding Institute of the Ukrainian National Academy of Sciences has been studying highfrequency welding of soft tissue in vivo since 1992 and applying it to clinical practice as an option for surgical suture. Before the 20th century, surgical sutures were needles and thread, made of natural materials. Although material and technology of the needle and thread suture have been improved in recent decades, needle and thread suture have the characteristics of long time, slow recovery, easy infection, easy scar, and obvious defect of wound, which bring great pain to patients and extend the operation time and postoperative recovery time. Therefore, human soft tissue welding is proposed, which uses high-frequency current to weld the human tissue. The welding principle is that by regulating and controlling the temperature generated by the high-frequency current, the cell membrane is destroyed, and proteins are released first, and then the current is further adjusted; pressure is applied to denature the proteins between cells by heat, causing winding and agglutination, so as to realize the connection of the wound binding interface. In the welding process, except for the special effects of highfrequency current and coincidence pressure, the welding position accuracy is the key factor. In the process of welding, it is necessary to ensure that the welding position is accurate and controlled within the scope of the wound. The above must be realized through the machine's continuous automatic adjustment of the position. To realize intelligent adjustment of the machine, a large number of experimental data and modulation strategy are needed to form the welding algorithm, which is the work we are currently performing. Rodts et al. [21] proposed the use of selective laser welding on the surface of three-dimensional fabrics to improve their wear resistance. Colic et al. [22] studied the applicability of laser welding in biomedical device manufacturing and analyzed stainless steel materials used in biomedical applications. The research results show that stainless steel has excellent forming and welding characteristics and can be used as a material for certain medical devices. There are some other methods that we can learn from [23-26].
The field of machine learning control in welding has been studied for many years [27-29]. With the development of computer control technology and with the help of iterative learning control, fuzzy control, PID, and other intelligent control methods, many robots and specific automatic welding equipment also have a certain self-learning function. They can not only simulate the learning perception of skilled operators but also transcend human limitations. They have the advantages of a large amount of information, no contact with the workpiece, high sensitivity and precision, and strong antielectromagnetic interference ability [30-33]. So, we introduce iterative learning control into automatic robot welding.

The history of iterative learning control $[34,35]$ can be traced back to 1984, when Arimoto proposed the learning rules of P, PI, and PID and successfully applied them to the motion control of robots. After that, closed-loop and openloop combination learning control laws appeared. Openclosed-loop ILC can extract current and previous track information simultaneously. Therefore, it is better than open-loop or closed-loop ILC in learning ability. Meanwhile, we add a system correction term into the ILC algorithm, which improves robustness and anti-interference of the system. The algorithm not only inherits the characteristics of the traditional ILC control, such as simple structure, high reliability, and easy engineering implementation, but also overcomes the shortcomings of the closed-loop controller, such as poor followability and inaccurate adjustment under strong interference, and has strong nonlinear and uncertain characteristics.

This paper is structured as follows: in Section 2, a mathematical model of the human soft tissue welding system is derived. A new designed ILC algorithm with the system correction term is proposed in Section 3. Section 4 describes the convergence and stability of this algorithm. Finally, the control system is implemented to verify the effectiveness and robustness of the control strategy through numerical simulation.

\section{Dynamic Model of the Welding System}

The human soft tissue welding robot is shown in Figure 1. The electrode is held on the electrode holder, extended from the nozzle of the welding gun, and welded through the part between one end of the electrode and the welded part of the human soft tissue. At the beginning of the welding process, the arc transfers heat to the human soft tissue, and the human soft tissue temperature rises rapidly. The proteins in the soft tissue melt and then stick together, like fried eggs. When suturing with the needle and thread, the skin easily leaves a scar, and immune response may also occur, but by stitching their own proteins together, they can heal on the spot and create shallower scars. During surgery, high-frequency current passing through the soft tissue will cause instantaneous thermal damage, thus achieving the purpose of cutting. Meanwhile, protein spill bonding can achieve hemostasis at the same time. In the process of protein overflow and bonding, the wound is closed, and the binding interface is connected. 


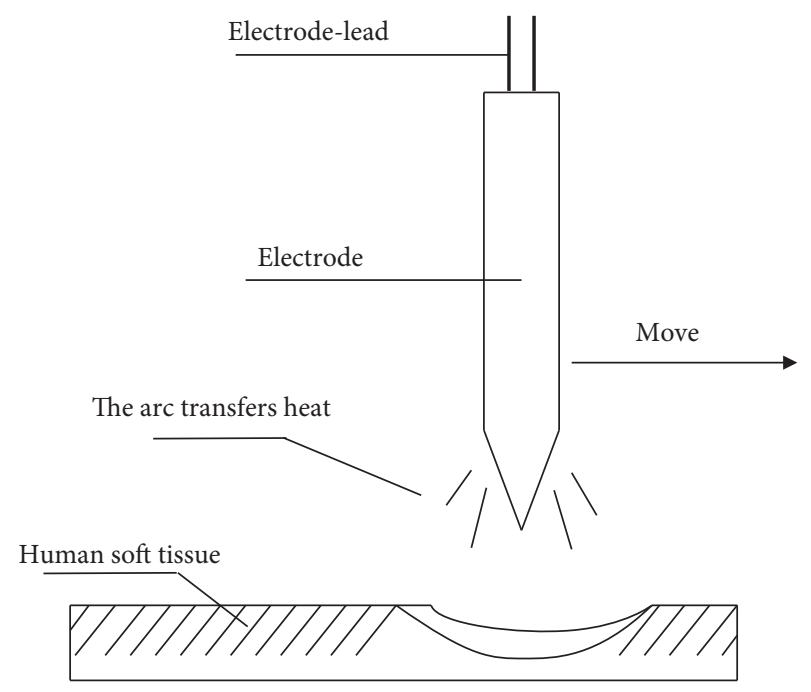

FIgURE 1: Welding schematic for biomedical applications. insufficient strength of the connection between tissues, so that the welding anastomosis is not firm enough, and the high incidence of postoperative complications is mainly due to the difficulty in controlling the position and current of the welding machine during the use. From the perspective of the view of system control, the crack at the wound can be controlled by adjusting the welding input. The biomedical welding process studied in this paper takes the welding current as the control input and the fracture position at the wound as the system output.

The dynamic characteristic model of the biomedical welding system is as follows:

$$
x(t)=\sum_{l=1}^{j} a_{l} x(t-l)+\sum_{h=1}^{k} b_{h} u(t-h),
$$

where $x(t)$ is the weld position, $u(t)$ is the welding current, $l$ and $h$ are the system time delay, $j=5$, and $k=6$.

Formula (1) can be written as

At present, the biggest disadvantage of welding technology is that it is easy to cause tissue burns, which lead to

$$
X(t)=\left[\begin{array}{c}
x(t) \\
x(t-1) \\
x(t-2) \\
x(t-3) \\
x(t-4)
\end{array}\right]=\left[\begin{array}{ccccc}
a 1 & a 2 & a 3 & a 4 & a 5 \\
1 & 0 & 0 & 0 & 0 \\
0 & 1 & 0 & 0 & 0 \\
0 & 0 & 1 & 0 & 0 \\
0 & 0 & 0 & 1 & 0
\end{array}\right]\left[\begin{array}{c}
x(t-1) \\
x(t-2) \\
x(t-3) \\
x(t-4) \\
x(t-5)
\end{array}\right]+\left[\begin{array}{cccccc}
b 1 & b 2 & b 3 & b 4 & b 5 & b 6 \\
0 & 0 & 0 & 0 & 0 & 0 \\
0 & 0 & 0 & 0 & 0 & 0 \\
0 & 0 & 0 & 0 & 0 & 0 \\
0 & 0 & 0 & 0 & 0 & 0
\end{array}\right]\left[\begin{array}{c}
u(t-1) \\
u(t-2) \\
u(t-3) \\
u(t-4) \\
u(t-5) \\
u(t-6)
\end{array}\right] .
$$

The equation of the state of model (1) is expressed as

$$
\left\{\begin{array}{l}
X(t)=A X(t-1)+B U(t) \\
Y(t)=C X(t), \quad\left[\begin{array}{ll}
a 1 & a 2
\end{array}\right.
\end{array}\right.
$$

where

$$
B=\left[\begin{array}{cccccc}
b 1 & b 2 & b 3 & b 4 & b 5 & b 6 \\
0 & 0 & 0 & 0 & 0 & 0 \\
0 & 0 & 0 & 0 & 0 & 0 \\
0 & 0 & 0 & 0 & 0 & 0 \\
0 & 0 & 0 & 0 & 0 & 0
\end{array}\right] \text {, and } C=I .
$$

\section{Designed ILC Algorithm with the System}

\section{Correction Term}

For welding system (3), the following iterative learning control algorithm is considered:

$$
\begin{aligned}
u_{i+1}(t)= & u_{i}(t)+\left(1+\cos \alpha_{i}\right) \varphi(t) e_{i}(t) \\
& +\left(1+\cos \alpha_{i+1}\right) \Psi(t) e_{i+1}(t),
\end{aligned}
$$

where $i$ indicates the iteration number, $\varphi(t), \Psi(t)$ are the learning gain matrices, and $e_{i}(t)=y_{d}(t)-y_{i}(t) . u_{i}(t)$ is the control variable. $\cos \alpha_{i}$ and $\cos \alpha_{i+1}$ are system correction terms. The designed iterative algorithm flow is shown in Figure 2.

We also set a special coefficient for the ILC law $[36,37]$ to determine the reward and punishment of the control law according to the effect of the control law. When the system output $y_{i}(t)$ is close to the expected output $y_{d}(t)$, the learning law correction can be enhanced. When the system output $y_{i}(t)$ is deviating from the expected output $y_{d}(t)$, the learning law correction can be weakened.

This paper not only considers the errors between the system output and the reference trajectory but also considers the spatial orientation relation between the three variables in the output vector space.

$$
\begin{aligned}
\cos \alpha_{i} & =\frac{e_{i}(t)\left(y_{i+1}(t)-y_{i}(t)\right)}{\left\|e_{i}(t)\right\|\left\|y_{i+1}(t)-y_{i}(t)\right\|}, \\
\cos \alpha_{i+1} & =\frac{e_{i+1}(t)\left(y_{i+2}(t)-y_{i+1}(t)\right)}{\left\|e_{i+1}(t)\right\|\left\|y_{i+2}(t)-y_{i+1}(t)\right\|} .
\end{aligned}
$$




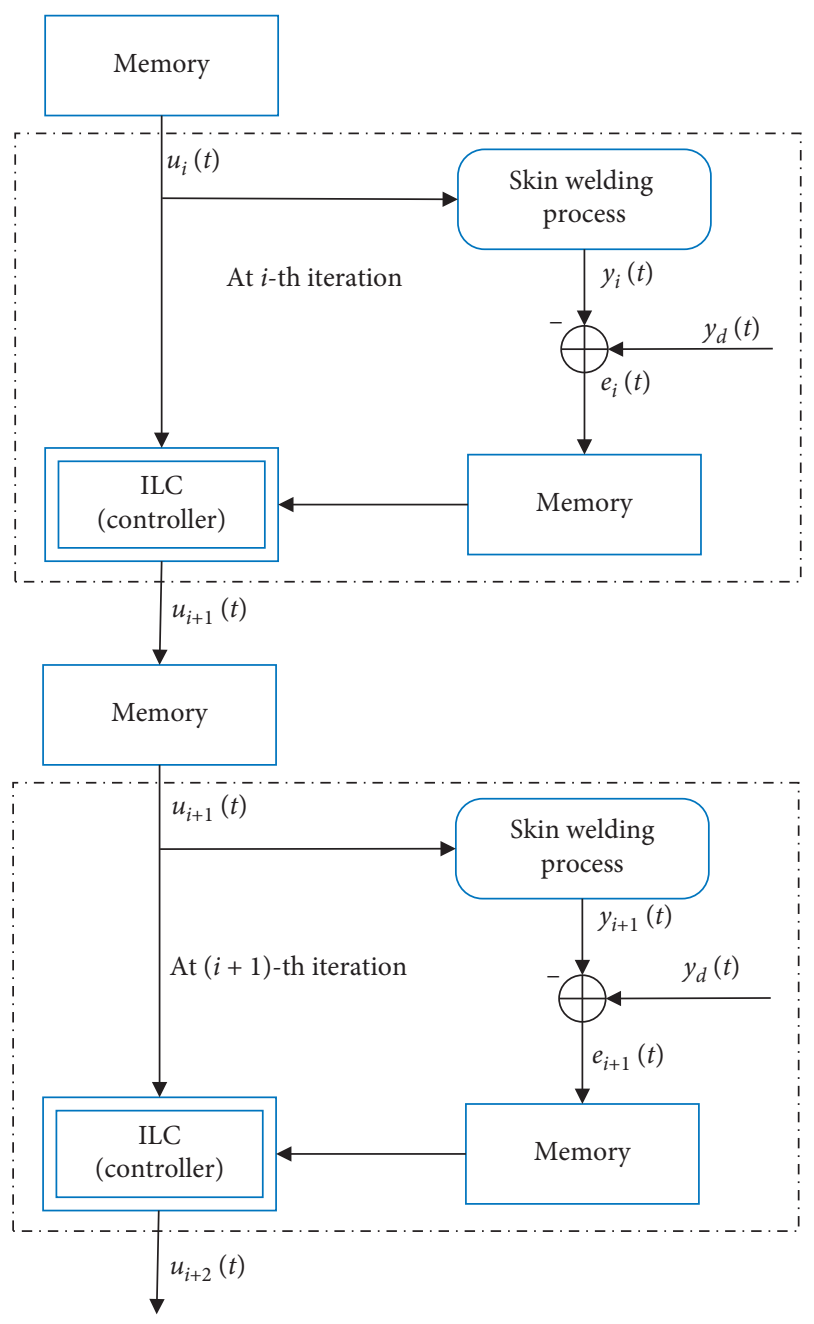

FIgURE 2: Welding schematic for biomedical applications.

It is the basis for judging the quality of the ILC law based on vector analysis. Let us simplify these formulas, $\widehat{\alpha}_{i} \triangleq(1+$ $\left.\cos \alpha_{i}\right)$ and $\widehat{\alpha}_{i+1} \triangleq\left(1+\cos \alpha_{i+1}\right)$.

\section{Problem Formulation}

The welding process is repeated at $[0, T]$. Let us consider the following welding process system with the interference and uncertainty terms:

$$
\left\{\begin{array}{l}
X_{i}(t)=A X_{i}(t-1)+B U_{i}(t)+\omega_{i}(t), \\
Y_{i}(t)=C X_{i}(t)+v_{i}(t),
\end{array}\right.
$$

where $i$ is the number of iterations, $t \in\{0,1, \ldots, T\}$, and $\omega_{i}(t)$ and $\nu_{i}(t)$ are the uncertainty item and interferential term, respectively.

Following are restrictions on ILC systems (4) and (6).

Assumption 1. The initial state of the system is the same every time.

Assumption 2. The expected output is the same, when the system runs every time.

Assumption 3. There exists $u_{d}(t)$ that makes the system state become $x_{d}(t)$ and system output become $y_{d}(t)$ for all $t \in[0, T]$.

$$
\left\{\begin{array}{l}
x_{d}(t)=A x_{i}(t-1)+B u_{d}(t)+\omega_{d}(t), \\
y_{d}(t)=C x_{d}(t),
\end{array}\right.
$$

where $x_{d}(t)$ is the expected state. In the actual welding process, the welding control system performing the repeated welding process meets the above three assumptions. The expected output in the welding process is a constant value, so it also meets Assumption 2. Assumption 3 is the condition of controllability for a given control task.

When the initial state of the system is $x_{i}(0)$, the solution of equation (6) can be written as

$$
x_{i}(t)=A^{t} x_{i}(0)+\sum_{s=0}^{t} A^{t-s} B u_{i}(s), \quad t \in\{0, T\} .
$$

Theorem 1. For the system described by equation (6), the given reachable expected trajectory is $y_{d}(t)$. If conditions (1) and (2) are satisfied,

$$
\begin{aligned}
& \text { (1) }\left\|\frac{(1-\Upsilon)-\varphi C B}{I+\Psi C B}\right\| \leq \rho<1, \quad t \in\{0, T\}, \\
& \text { (2) } x_{i}(0)=x_{d}(0), \quad i=0,1,2, \ldots,
\end{aligned}
$$

then the learning rate (4) makes the output trajectory to uniformly converge to the expected trajectory. When $i \longrightarrow \infty$, we have $y_{i}(t) \longrightarrow y_{d}(t)(t \in[0, T+1])$.

Proof. Let us consider the control error at the $i+1$ iteration:

$$
\begin{aligned}
\Delta u_{i+1}(t)= & u_{d}(t)-u_{i+1}(t)=u_{d}(t)-u_{i}(t)-\varphi \widehat{\alpha}_{i} e_{i}(t)-\Psi \widehat{\alpha}_{i+1} e_{i+1}(t) \\
= & \Delta u_{i}(t)-\varphi \widehat{\alpha}_{i}\left[y_{d}(t)-y_{i}(t)\right]-\Psi \hat{\alpha}_{i+1}\left[y_{d}(t)-y_{i+1}(t)\right] \\
= & \Delta u_{i}(t)-\varphi \widehat{\alpha}_{i} C \Delta x_{i}(t)-\Psi \widehat{\alpha}_{i+1} C \Delta x_{i+1}(t)+\varphi \widehat{\alpha}_{i} C v_{i}(t)+\Psi \widehat{\alpha}_{i+1} C v_{i+1}(t) \\
= & \Delta u_{i}(t)-\varphi \widehat{\alpha}_{i} C\left[A \Delta x_{i}(t-1)+B \Delta u_{i}(t)+\Delta \omega_{i}(t)\right] \\
& -\Psi \widehat{\alpha}_{i+1} C\left[A \Delta x_{i+1}(t-1)+B \Delta u_{i+1}(t)+\Delta \omega_{i+1}(t)\right]+\varphi \widehat{\alpha}_{i} C v_{i}(t)+\Psi \widehat{\alpha}_{i+1} C v_{i+1}(t) .
\end{aligned}
$$


Then, equation (10) could be rewritten as

$$
\begin{aligned}
\left(I+\Psi \widehat{\alpha}_{i+1} C B\right) \Delta u_{i+1}(t)= & \left(I-\varphi \widehat{\alpha}_{i} C B\right) \Delta u_{i}(t)-\varphi \widehat{\alpha}_{i} C A \Delta x_{i}(t-1) \\
& -\Psi \widehat{\alpha}_{i+1} C A \Delta x_{i+1}(t-1)+\varphi \widehat{\alpha}_{i} C\left(v_{i}(t)-\Delta \omega_{i}(t)\right)+\Psi \widehat{\alpha}_{i+1} C\left(v_{i+1}(t)-\Delta \omega_{i+1}(t)\right) .
\end{aligned}
$$

Take the norm at both ends of formula (11):

$$
\begin{aligned}
\left\|I+\Psi \widehat{\alpha}_{i+1} C B\right\|\left\|\Delta u_{i+1}(t)\right\|= & \left\|I-\varphi \widehat{\alpha}_{i} C B\right\|\left\|\Delta u_{i}(t)\right\|+\left\|\varphi \widehat{\alpha}_{i} C A\right\|\left\|\Delta x_{i}(t-1)\right\| \\
& +\left\|\Psi \widehat{\alpha}_{i+1} C A\right\|\left\|\Delta x_{i+1}(t-1)\right\|+\left\|\varphi \widehat{\alpha}_{i} C\right\|\left\|v_{i}(t)-\Delta \omega_{i}(t)\right\|+\left\|\Psi \widehat{\alpha}_{i+1} C\right\|\left\|\nu_{i+1}(t)-\Delta \omega_{i+1}(t)\right\| .
\end{aligned}
$$

Equation (12) could be rewritten as

$$
\begin{aligned}
\left\|\Delta u_{i+1}(t)\right\| \leq & \left\|\frac{I-\varphi \hat{\alpha}_{i} C B}{I+\Psi \hat{\alpha}_{i+1} C B}\right\|\left\|\Delta u_{i}(t)\right\|+\left\|\frac{\varphi \widehat{\alpha}_{i} C A}{I+\Psi \hat{\alpha}_{i+1} C B}\right\|\left\|\Delta x_{i}(t-1)\right\| \\
& +\left\|\frac{\Psi \hat{\alpha}_{i+1} C A}{I+\Psi \hat{\alpha}_{i+1} C B}\right\|\left\|\Delta x_{i+1}(t-1)\right\|+\left\|\frac{\varphi \hat{\alpha}_{i} C+\Psi \widehat{\alpha}_{i+1} C}{I+\Psi \hat{\alpha}_{i+1} C B}\right\|\left(\zeta_{\nu}-\zeta_{\omega}\right) \\
\leq & \rho\left\|\Delta u_{i}(t)\right\|+\eta_{1}\left\|\Delta x_{i}(t-1)\right\|+\eta_{3}\left\|\Delta x_{i+1}(t-1)\right\|+\Theta,
\end{aligned}
$$

where $\quad \eta_{1}=\left\|\varphi \widehat{\alpha}_{i} C A /\left(I+\Psi \hat{\alpha}_{i+1} C B\right)\right\|, \quad \eta_{3}=\| \Psi \widehat{\alpha}_{i+1} C A /$ $\left(I+\Psi \widehat{\alpha}_{i+1} C B\right)\|, \quad \rho=\|\left(I-\varphi \widehat{\alpha}_{i} C B\right) /\left(I+\Psi \widehat{\alpha}_{i+1} C B\right) \|$, $\zeta_{v}=\max _{t \in[0, T]}\left\{\sup \left\|v_{i}(t)\right\|, \sup \left\|v_{i+1}(t)\right\|\right\}$,

$\zeta_{\omega}=\max _{t \in[0, T]}\left\{\sup \left\|\Delta \omega_{i}(t)\right\|, \sup \left\|\Delta \omega_{i+1}(t)\right\|\right\}$, and $\Theta=\left\|\left(\varphi \widehat{\alpha}_{i} C+\Psi \widehat{\alpha}_{i+1} C\right) /\left(I+\Psi \widehat{\alpha}_{i+1} C B\right)\right\|\left(\zeta_{\nu}-\zeta_{\omega}\right)$.

Using formula (8), formula (12) can be written as

$$
\begin{aligned}
\left\|\Delta u_{i+1}(t)\right\| & \leq \rho\left\|\Delta u_{i}(t)\right\|+\eta_{1} \sum_{s=0}^{t-1}\left\|A^{t-s} B\right\|\left\|\Delta u_{i}(s)\right\|+\eta_{3} \sum_{s=0}^{t-1}\left\|A^{t-s} B\right\|\left\|\Delta u_{i+1}(s)\right\|+\Theta \\
& \leq \rho\left\|\Delta u_{i}(t)\right\|+\eta_{1} \eta_{2} \sum_{s=0}^{t-1}\left\|\Delta u_{i}(s)\right\|+\eta_{3} \eta_{2} \sum_{s=0}^{t-1}\left\|\Delta u_{i+1}(s)\right\|+\Theta,
\end{aligned}
$$

where $1 \leq t \leq T$ and $\eta_{2}=\sup _{0<s \leq t-1}\left\|A^{t-s} B\right\|$.

Multiplying both sides of formula (14) by $\lambda^{t}(0<\lambda<1)$, we obtain 


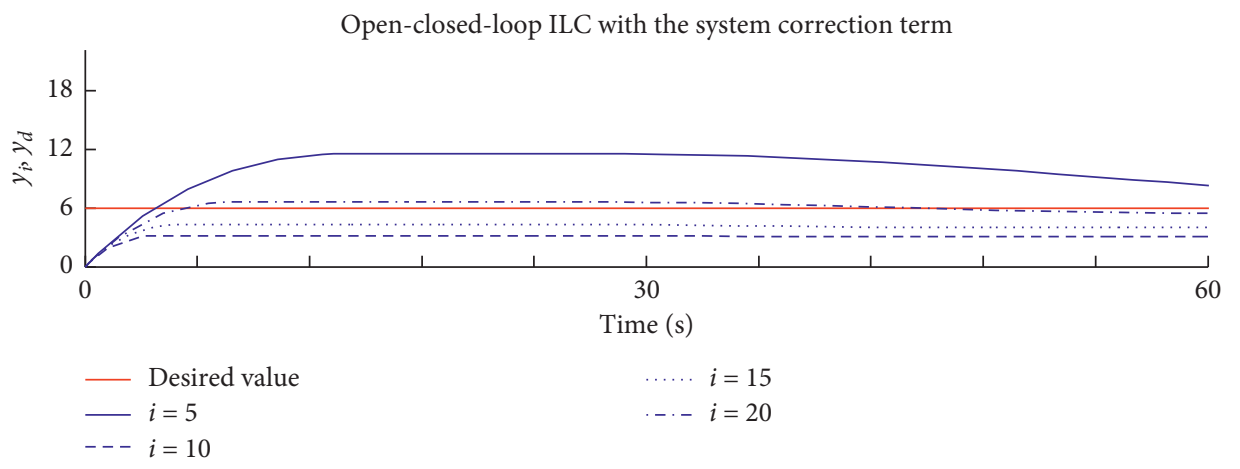

FIgURE 3: Tracking curve of biowelding with the system correction term.

$$
\begin{aligned}
\lambda^{t}\left\|\Delta u_{i+1}(t)\right\| & \leq \rho \lambda^{t}\left\|\Delta u_{i}(t)\right\|+\eta_{1} \eta_{2} \sum_{s=0}^{t-1} \lambda^{t-s} \lambda^{s}\left\|\Delta u_{i}(s)\right\|+\eta_{3} \eta_{2} \sum_{s=0}^{t-1} \lambda^{t-s} \lambda^{s}\left\|\Delta u_{i+1}(s)\right\|+\Theta \\
& \leq \rho \lambda^{t}\left\|\Delta u_{i}(t)\right\|+\eta_{1} \eta_{2} \sum_{s=0}^{t-1} \lambda^{t-s} \sup _{0 \leq \tau \leq T}\left\{\lambda^{\tau}\left\|\Delta u_{i}(\tau)\right\|\right\}+\eta_{3} \eta_{2} \sum_{s=0}^{t-1} \lambda^{t-s} \sup _{0 \leq \tau \leq T}\left\{\lambda^{\tau}\left\|\Delta u_{i+1}(\tau)\right\|\right\}+\Theta \\
& \leq \rho \lambda^{t}\left\|\Delta u_{i}(t)\right\|+\eta_{1} \eta_{2} \sum_{s=0}^{t-1} \lambda^{t-s}\left\|\Delta u_{i}\right\|_{\lambda}+\eta_{3} \eta_{2} \sum_{s=0}^{t-1} \lambda^{t-s}\left\|\Delta u_{i+1}\right\|_{\lambda}+\Theta \\
& \leq \rho \lambda^{t}\left\|\Delta u_{i}(t)\right\|+\eta_{1} \eta_{2} \frac{\lambda\left(1-\lambda^{T}\right)}{1-\lambda}\left\|\Delta u_{i}\right\|_{\lambda}+\eta_{3} \eta_{2} \frac{\lambda\left(1-\lambda^{T}\right)}{1-\lambda}\left\|\Delta u_{i+1}\right\|_{\lambda}+\Theta .
\end{aligned}
$$
get

According to formula (13) and the definition of norm, we

$$
\left\|\Delta u_{i+1}\right\|_{\lambda} \leq \tilde{\rho}\left\|\Delta u_{i}\right\|_{\lambda}+\Theta
$$

where $\quad \tilde{\rho}=\left(\left(\rho(1-\lambda)+\eta_{1} \eta_{2} \lambda\left(1-\lambda^{T}\right)\right) /\left(1-\lambda-\eta_{3} \eta_{2} \lambda\right.\right.$ $\left.\left.\left(1-\lambda^{T}\right)\right)\right)$.

When $\rho<1$, we can get $\lim _{i \rightarrow \infty}\left\|\Delta u_{i}\right\|_{\lambda} \leq(\Theta /(1-\tilde{\rho}))$. According to formulas (6) and (8), when $0<\lambda<1$, we get

$$
\lambda^{t}\left\|e_{i}(t)\right\| \leq\|C\| \sum_{s=0}^{t-1}\left\|A^{t-s} B\right\| \lambda^{t-s} \lambda^{s}\left\|\Delta u_{i}(s)\right\| \leq \widehat{c} \eta_{2} \sum_{s=0}^{t-1} \lambda^{t-s}\left\|\Delta u_{i}\right\|_{\lambda} \leq \widehat{c} \eta_{2} \frac{\lambda\left(1-\lambda^{T}\right)}{1-\lambda}\left\|\Delta u_{i}\right\|_{\lambda} \text {, }
$$

where $1 \leq t \leq T+1$ and $\widehat{c}=\|C\|$.

According to the definition of $\lambda$-norm,

$$
\sup _{1 \leq t \leq T+1}\left\{\lambda^{t}\left\|e_{i}(t)\right\|\right\} \leq \widehat{c} \eta_{2} \frac{\lambda\left(1-\lambda^{T}\right)}{1-\lambda}\left\|\Delta u_{i}\right\|_{\lambda} .
$$

So, $\lim _{i \longrightarrow \infty} \sup _{1 \leq t \leq T+1}\left\{\lambda^{t}\left\|e_{i}(t)\right\|\right\} \leq(\Theta /(1-\tilde{\rho}))$. We find that the tracking error bound converges to a small neighborhood of the origin, and we can reach the conclusion $y_{i}(t) \longrightarrow y_{d}(t)(i \longrightarrow \infty)$.

\section{Simulations}

In this paper, MATLAB is used for simulation to verify the feasibility of the proposed algorithm in the biomedical welding system. Let us set the input initial value as $u_{i}(t)=0$ at each iteration. The expected trajectory is $y_{d}(t)=6 \mathrm{~mm}$.
The data used in the simulation are $\varphi(t)=0.19, \Psi(t)=0.24$, and $\omega_{i}(t)=0.0015 \cos (0.1 \pi t)$.

After the biomedical welding system is learned for 5 times, 10 times, 15 times, and 20 times respectively, the effect of the welding process and trace control is shown in Figures 3 and 4. As shown in Figures 3 and 4, after 20 iterations, the effect of the tracking control system can be reached quickly, and the error of the tracking control is smaller than $0.02 \mathrm{~mm}$. After 20 seconds, Figures 5 and 6 show that the maximum value of the error absolute pair in each welding pass varies with the number of welds, and it can be seen that the tracking error gradually converges to zero as the iteration number increases. Each initial state is reset to zero. The initial point of the desired trajectory and the initial point of the output trajectory are not together, but after 20 seconds, the actual trajectory can coincide with the desired trajectory. This means that the position control 


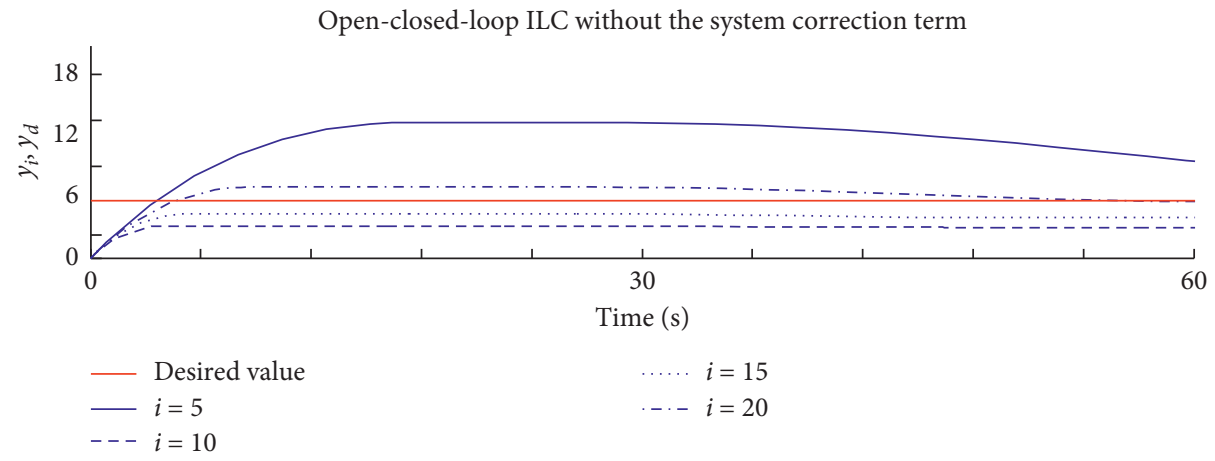

FIGURE 4: Tracking curve of biowelding without the system correction term.

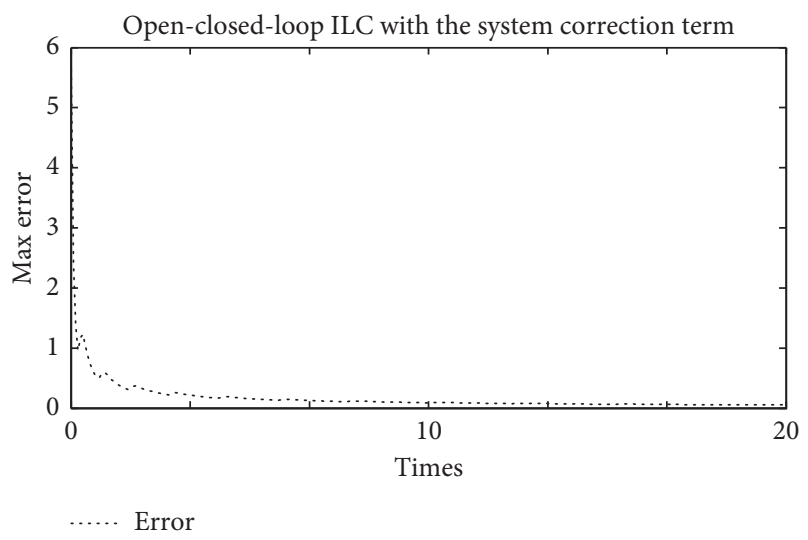

Figure 5: Maximum tracking error in iteration times with the system correction term after 20 seconds.

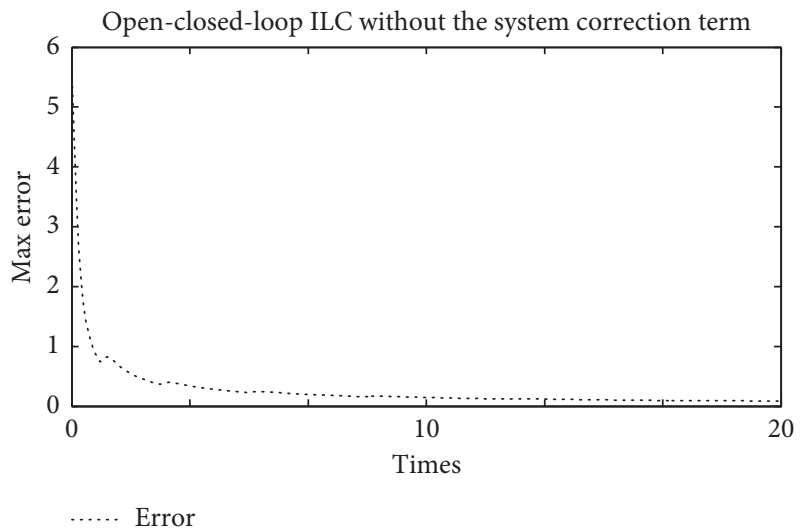

Figure 6: Maximum tracking error in iteration times without the system correction term after 20 seconds.

of medical welding reaches the expected value, which proves the effectiveness of the iterative algorithm for the process control of biomedical welding.

Through the comparison of multigraph data, the iterative learning algorithm with modified items has less oscillation in the process of biological welding and achieves better tracking control effect. Moreover, it is obvious that the new iterative algorithm has a faster convergence rate than the traditional iterative algorithm and a smaller final error. The algorithm proposed in this paper can well suppress the effect of disturbance so that the tracking control system of the output opposition value of the control system is almost influenced, and the control system is still controlled within the range of $0.02 \mathrm{~mm}$. Because of this, the new iterative control system can suppress the nonrepeatability disturbance in the process of biological welding with certain inhibition energy and obtain a better control effect than the traditional algorithm.

\section{Conclusions}

In this paper, ILC algorithm is used to study the tracking problem of the biomedical welding system. The proposed intelligent ILC algorithm makes full use of the advantages of p-type ILC and system correction terms. The ILC algorithm is applied to the biomedical welding system to improve the tracking performance of repetitive tasks and to deal with the uncertainty of the model. Sufficient conditions are given to ensure the convergence and robustness of the open-loop ILC system. Finally, the effectiveness of the proposed ILC scheme in the biomedical welding system is demonstrated by a simulation example. Future work will be focused on the implementation of intelligent optimization methods to adjust the learning gain matrix for ILC control recommendations in the human soft tissue welding robot.

\section{Data Availability}

The data used to support the findings of this study are currently under embargo, while the research findings are commercialized. Requests for data 6 months after publication of this article will be considered by the corresponding author.

\section{Conflicts of Interest}

The authors declare that there are no conflicts of interest regarding the publication of this paper.

\section{Acknowledgments}

This work was supported in part by Jiangsu Colleges and Universities Natural Science Research of China (Grant no. 20KJB210012). 


\section{References}

[1] M. P. Shankar, R. Sokkalingam, K. Sivaprasad, and V. Muthupandi, "Correlating tensile properties with microstructures of various regions in gas tungsten arc welded AA2014 alloy," Materials Science Forum, vol. 969, pp. 22-26, 2019.

[2] P. Roshith, M. Arivarasu, N. Arivazhagan, A. Srinivasan, and K. V. Phani Prabhakar, "Investigations on induced residual stresses, mechanical and metallurgical properties of $\mathrm{CO}_{2}$ laser beam and pulse current gas tungsten arc welded SMO 254," Journal of Manufacturing Processes, vol. 44, pp. 81-90, 2019.

[3] S. Varin, M. Agarwal, A. Chugh et al., "Effect of laser shock peening on commercially pure titanium-1 weldment fabricated by gas tungsten arc welding technique," Transactions of the Indian Institute of Metals, vol. 72, no. 6, pp. 1569-1573, 2019.

[4] E. F. Shultz, A. Fehrenbacher, F. E. Pfefferkorn, M. R. Zinn, and N. J. Ferrier, "Shared control of robotic friction stir welding in the presence of imperfect joint fit-up," Journal of Manufacturing Processes, vol. 15, no. 1, pp. 25-33, 2013.

[5] I.-D. Park, K.-W. Nam, and C.-Y. Kang, "Shear strength of ball studs according to the resistance welding conditions \& reliability testing based on the weibull distribution function," Journal of Mechanical Science and Technology, vol. 32, no. 12, pp. 5647-5652, 2018.

[6] M. Hirohata, F. Takeda, M. Suzaki, K. Inose, N. Matsumoto, and D. Abe, "Influence of laser-arc hybrid welding conditions on cold cracking generation," Welding in the World, vol. 63, no. 5, pp. 1407-1416, 2019.

[7] B. Venkatesh, B. Malvi, M. Roy, and P. Sarkar, "Effect of welding conditions on erosive wear of hard-faced Co-based alloy layer," Proceedings of the Institution of Mechanical Engineers, Part J: Journal of Engineering Tribology, vol. 232, no. 11, pp. 1377-1389, 2018.

[8] K. Kimapong and S. Triwanapong, "Influence of gas metal arc welding parameter on lap joint properties of SS400 carbon steel and SUS304 stainless steel," Key Engineering Materials, vol. 789, pp. 110-114, 2018.

[9] M. Hu, "WELDOX960 low alloy high strength steel welding automation manufacturability research," Key Engineering Materials, vol. 748, pp. 284-287, 2017.

[10] J. Thongsri and M. Pimsarn, "Optimum airflow to reduce particle contamination inside welding automation machine of hard disk drive production line," International Journal of Precision Engineering and Manufacturing, vol. 16, no. 3, pp. 509-515, 2015.

[11] A.-C. Hesse, J. Hensel, T. Nitschke-Pagel, and K. Dilger, "Investigations on the fatigue strength of beam-welded butt joints taking the weld quality into account," Welding in the World, vol. 63, no. 5, pp. 1303-1313, 2019.

[12] N. Lv, J. Zhong, J. Wang, and S. Chen, “Automatic measuring and processing system of audio sensing for real-time arc height control of pulsed GTAW," Sensor Review, vol. 34, no. 1, pp. 51-66, 2014.

[13] T. Suto, Y. Iwamoto, and Y. Suga, "304 visual recognition and automatic tracking control of welding line by mobile welding robot," in Proceedings of the 2000 Materials and Processing Conference, San Francisco, CA, USA, 2000, https://www. researchgate.net/publication/317891497_304_Visual_Recogniti on_and_Automatic_Tracking_Control_of_Welding_Line_by_ Mobile_Welding_Robot.

[14] S. Nakata and H. Jie, "Construction of a visual sensing system for in-process control of arc welding and its application in automatic weld line tracking — study on visual sensing systems for in-process control of arc welding (4th report)," Welding International, vol. 4, no. 11, pp. 845-850, 1990.

[15] N. Lv, Y. Xu, S. Li, X. Yu, and S. Chen, "Automated control of welding penetration based on audio sensing technology," Journal of Materials Processing Technology, vol. 250, pp. 81-98, 2017.

[16] N. Lv, J. Zhong, H. Chen, T. Lin, and S. Chen, "Real-time control of welding penetration during robotic GTAW dynamical process by audio sensing of arc length," The International Journal of Advanced Manufacturing Technology, vol. 74, no. 1-4, pp. 235-249, 2014.

[17] T. Lin, H. B. Chen, W. H. Li, and S. B. Chen, "Intelligent methodology for sensing, modeling, and control of weld penetration in robotic welding system," Industrial Robot: An International Journal, vol. 36, no. 6, pp. 585-593, 2009.

[18] L. Di, T. Srikanthan, R. S. Chandel, and I. Katsunori, "Neuralnetwork-based self-organized fuzzy logic control for arc welding," Engineering Applications of Artificial Intelligence, vol. 14, no. 2, pp. 115-124, 2001.

[19] X. Gao, S. Huang, and Y. Yu, "Study on the neural network control for seam tracking of arc-welding robot," Journal of Mechanical Engineering, vol. 36, pp. 115-124, 2001.

[20] Z. G. Yan, D. Xu, Y. Li et al., "A visual servoing system for the torch alignment to initial welding position," Lecture Notes in Computer Science (LNCS), vol. 5315, pp. 697-706, SpringerVerlag, Berlin, Germany, 2008.

[21] T. Rodts, S. R. Schmid, M. A. Selles, T. Pasang, and S. SanchezCaballero, "Selective laser fiber welding on woven polymer fabrics for biomedical applications," Materials Science and Engineering: C, vol. 94, pp. 628-634, 2019.

[22] K. Colic, S. Petronic, A. Sedmak, A. Milosavljevic, and Z. Kovacevic, "Laser welding process of stainless steel used for biomedical applications," Materials Science and Engineering: C, vol. 20, 2018.

[23] S. Mobayen, M. J. Yazdanpanah, and V. J. Majd, “A finite-time tracker for nonholonomic systems using recursive singularityfree FTSM," in Proceedings of the 2011 American Control Conference, IEEE, San Franisco, CA, USA, 2011.

[24] S. Mobayen and F. Tchier, "Nonsingular fast terminal sliding mode stabilizer for a class of uncertain nonlinear systems based on disturbance observer," Entia Iranica, vol. 24, no. 3, 2017.

[25] S. Mobayen, "Design of LMI-based sliding mode controller with an exponential policy for a class of underactuated systems," Complexity, vol. 21, no. 5, pp. 117-124, 2016.

[26] M. Saleh and M. Jun, "Robust finite-time composite nonlinear feedback control for synchronization of uncertain chaotic systems with nonlinearity and time-delay," Chaos Solitons \& Fractals, vol. 114, pp. 46-54, 2018.

[27] M. Juhola, H. Joutsijoki, K. Penttinen, and K. Aalto-Setälä, "Machine learning to differentiate diseased cardiomyocytes from healthy control cells," Informatics in Medicine Unlocked, vol. 14, pp. 15-22, 2019.

[28] C. K. Wee and R. Nayak, "A novel machine learning approach for database exploitation detection and privilege control," Journal of Information and Telecommunication, vol. 3, no. 3, pp. 308-325, 2019.

[29] N. Hiranuma, S. M. Lundberg, and S.-I. Lee, "AIControl: replacing matched control experiments with machine learning improves ChIP-seq peak identification," Nucleic Acids Research, vol. 47, no. 10, pp. 58-65, 2019.

[30] L. Ma, X. Huo, and X. Zhao, "Adaptive fuzzy tracking control for a class of uncertain switched nonlinear systems with 
multiple constraints: a small-gain approach," International Journal of Fuzzy Systems, vol. 21, no. 9, pp. 2609-2624, 2019.

[31] L. Ma, G. Zong, and X. Zhao, "Observed-based adaptive finitetime tracking control for a class of nonstrict-feedback nonlinear systems with input saturation," Journal of the Franklin Institute, vol. 357, no. 3, pp. 1-10, 2019.

[32] Y. Chang, Y. Wang, F. E. Alsaadi, and G. Zong, "Adaptive fuzzy output-feedback tracking control for switched stochastic pure-feedback nonlinear systems," International Journal of Adaptive Control and Signal Processing, vol. 33, no. 10, pp. 1567-1582, 2019.

[33] L. Ma, N. Xu, and X. Huo, "Adaptive finite-time outputfeedback control design for switched pure-feedback nonlinear systems with average dwell time," Nonlinear Analysis Hybrid Systems, vol. 37, pp. 100-108, 2020.

[34] D. Luo, J. Wang, D. Shen, and M. Fečkan, "Iterative learning control for fractional-order multi-agent systems," Journal of the Franklin Institute, vol. 356, no. 12, pp. 6328-6351, 2019.

[35] Y. Zhang, J. Liu, and X. Ruan, "Iterative learning control for uncertain nonlinear networked control systems with random packet dropout," International Journal of Robust and Nonlinear Control, vol. 29, no. 11, pp. 6328-6351, 2019.

[36] S. Lee and J. Park, "Iterative measurement for precise welding plane detection," in Proceedings of the 2013 International Conference on Ubiquitous Robots \& Ambient Intelligence, Jeju, Republic of Korea, 2013.

[37] Y. Liu and Y. Zhang, "Iterative local ANFIS-based human welder intelligence modeling and control in pipe GTAW process: a data-driven approach," IEEE/ASME Transactions on Mechatronics, vol. 20, no. 3, pp. 1079-1088, 2015. 